\title{
Caracterização e influência do teor do resíduo de areia de fundição fenólica em argamassas de revestimento
}

\author{
Characterisation and influence of the content of waste \\ foundry sand on rendering mortars
}

\section{J uliana Machado Casali \\ Thainá Fortunato Miguel \\ Caroline Castanhetti Felizardo \\ Natacha dos Santos Meira \\ Lucas Dominguini \\ Andrea Murillo Betioli}

\section{Resumo}

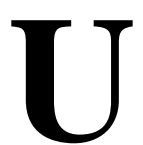

m dos resíduos gerados pela indústria de fundição que tem potencial de aplicação na construção civil é a areia de fundição. O objetivo deste trabalho foi caracterizar e verificar a influência do teor do resíduo de areia de fundição fenólica em argamassas de revestimentos

trabalháveis. Foram confeccionadas argamassas mistas, substituindo a areia natural, em volume, nos teores de 0\%, 10\%, 30\% e 100\% pelo resíduo de areia de fundição. Para os resíduos de areia de fundição e das argamassas foram realizados ensaios de corrosividade, reatividade, lixiviação e solubilização. Com os dados obtidos foi possível verificar a influência do resíduo de areia de fundição nas propriedades do estado fresco (principalmente na argamassa com 100\% do resíduo de areia de fundição, que demandou uma quantidade de água maior para a mesma consistência) e do endurecido (redução nas resistências, na densidade de massa e no módulo de elasticidade). Notou-se que as argamassas com resíduos de areia de fundição, em comparação com o resíduo de areia de fundição, apresentaram menor

J uliana Machado Casali Instituto Federal de Santa Catarina Florianópolis - SC - Brasil

Thainá Fortunato Miguel Instituto Federal de Santa Catarina Criciúma - SC - Brasil

Caroline Castanhetti Felizardo Instituto Federal de Santa Catarina Criciúma - SC - Brasil

Natacha dos Santos Meira Instituto Federal de Santa Catarina E-mail: Criciúma - SC - Brasil

Lucas Dominguini Instituto Federal de Santa Catarina Criciúma - SC - Brasil

Andrea Murillo Betioli Instituto Federal de Santa Catarina Florianópolis - SC - Brasil

Recebido em 31/03/16 Aceito em 17/04/17 concentração de ferro, fluoreto e sódio, e maior de alumínio, cromo total e fenóis totais. Os resíduos estudados foram classificados como não perigosos - Classe II A - não inertes, segundo a NBR 10004 (ABNT, 2004).

Palavras-chave: Areia de fundição. Argamassa de revestimento. Resíduo.

\section{Abstract}

Waste foundry sand is a waste product generated by the foundry industry that has potential applications in construction. The aim of this study was to characterise and evaluate the influence of phenolic foundry waste sand content on rendering workable mortars. Mortars were produced (using Portland cement and lime) replacing natural sand at $0 \%, 10 \%, 30 \%$ and $100 \%$ (in volume) with waste foundry sand. Corrosivity tests, reactivity tests, leaching extract assessments and solubilized extraction of solid waste were performed on the waste foundry sand and the waste of the studied mortars. The results demonstrated that the waste foundry sand had an influence on the properties of the mortars in fresh state (mainly for the mortar with $100 \%$ waste foundry sand, which required the use of a larger amount of water to obtain the same consistence) and in the hardened state (decrease in strength, mass density and modulus of elasticity). We observed that, comparing with the waste foundry sand itself, the mortar with the waste foundry sand had lower concentrations of iron, fluoride and sodium when, but higher concentrations of aluminium, chromium and total phenolics. The waste studied was classified as non-dangerous - Class II A - non-inert according to NBR 10004 (ABNT, 2004).

Keywords: Waste foundry sand. Rendering mortar. Waste. 


\section{Introdução}

No Brasil, segundo a Associação Brasileira de Fundição (ASSOCIAÇÃO..., 2016), a produção de fundidos de ferro total foi de 131.262 toneladas em janeiro de 2016. Dessa produção aproximadamente $22 \%$ seriam de resíduo de areia, segundo levantamento realizado por Lopes (2009). De acordo com Scheunemann (2005), somente na região de Criciúma, no Estado de Santa Catarina, são descartadas cerca de 500 toneladas de areia por mês. A maioria desses resíduos é encaminhada a aterros industriais ou depositada de forma incorreta no meio ambiente.

Os estudos demonstram que a preocupação com a poluição ambiental de preservação dos recursos naturais desperta 0 interesse de diversos pesquisadores na investigação da utilização desse resíduo, principalmente na área da construção civil. O uso desse resíduo pode ser observado em pesquisas nacionais em produtos à base de cimento Portland, como argamassas (ARMANGE, 2005; KRUGER; CABRAL; SOUZA, 2013; FERREIRA; FERREIRA; SILVA, 2011; TOLEDO et al., 2013; MELLO, 2004; MIGUEL et al., 2015); bloco de concreto (DAMASCENO; AMERICO, 2012); pavimentos de concreto (WATANABE, 2004); pisos de concreto (GENZLER, 2010); concreto (DAL MAGRO; MORAES; KULAKOWSKI, 2010); e concretos autoadensáveis (ROCHA; LUZ; HERMANN, 2012). Também é possível verificar pesquisas internacionais em concreto (SIDDIQUE; SCHUTTER; NOUMOWE, 2008; SINGH; SIDDIQUE, 2012; AGGARWAL; SIDDIQUE, 2014; KHATIB; HERKI; KENAI, 2013; SARASWATI et al., 2013) e em argamassa (SWAPNA; PATIL, 2015; KHANDURI, 2010).

Em relação aos trabalhos publicados na área de resíduo de areia fundição, deve-se levar em consideração a composição desse resíduo, que pode ser distinta conforme as matérias-primas utilizadas para as confecções dos moldes das peças metálicas nas fundições. Atualmente, a fabricação dos moldes é feita por dois processos diferentes, conforme Scheunemann (2005): o primeiro utiliza areia, bentonita e pó de carvão (denominada como "areia verde”); e o segundo processo utiliza areia, resina fenólica e pó de carvão (denominada "areia ligada quimicamente”). Os estudos desenvolvidos em argamassa por Armange (2003), Kruger, Cabral e Souza (2013), Mello (2004) e Khanduri (2010) utilizaram "areia verde”; e os estudos realizados por Ferreira, Ferreira e Silva (2011), Toledo et al. (2013) e Miguel et al. (2015) utilizaram "areia quimicamente ligada”. Desse modo, os resíduos de areias de fundição são distintos, então sua incorporação pode influenciar de forma diferente nas propriedades dos materiais. Assim, uma análise crítica dos resultados obtidos por cada autor em relação ao tipo de resíduo utilizado deve ser realizada.

Outro fator a ser considerado é que na grande maioria dessas pesquisas o resíduo é uma areia muito fina e é classificado como um resíduo sólido não perigoso - Classe II - não inerte, segundo a NBR 10004 (ABNT (2004), Toledo et al. (2013), Mello (2004), Armange et al. (2005), entre outros), o que demonstra a necessidade de se determinar a toxidade do resíduo e, também, dos materiais produzidos ele, como, por exemplo, a argamassa, através de ensaios de lixiviação e de solubilização. Entre as pesquisas citadas, a que avaliou essa propriedade foi a de Armange et al. (2005), com resíduo de areia de fundição ("areia verde”) em argamassa. Com relação aos ensaios de lixiviação, os autores observaram que o resíduo não apresenta influência na concentração dos extratos lixiviados. Para os ensaios de solubilização, os autores observaram que todas as argamassas apresentaram excesso de alumínio e que uma das argamassas com resíduo apresentou excesso de fluoretos.

Também é importante mencionar que a maioria das pesquisas em argamassas avalia a influência da substituição do resíduo de areia de fundição em massa pelo agregado miúdo natural e com relação água-cimento fixa (como nos estudos de Khanduri (2010); Kruger, Cabral e Souza (2013); Ferreira, Ferreira e Silva (2011); Toledo et al. (2013); e Armange (2005)), e não em argamassas consideradas trabalháveis, isto é, argamassas com facilidade de mistura, transporte, aplicação e consolidação. Além disso, normalmente são utilizados traços extremamente ricos em cimento Portland, como o traço 1:3 (cimento:areia), em massa, utilizado por Armange (2003), Kruger, Cabral e Souza (2013), Ferreira, Ferreira e Silva (2011), Toledo et al. (2013) e Khanduri (2010), sendo esse traço recomendado para avaliar a resistência à compressão do cimento Portland, conforme a NBR 7215 (ABNT, 1996), e não um traço usual para argamassas de revestimento. Segundo Lima e Betioli (2012), para argamassas de revestimento na região de Criciúma, utiliza-se cimento Portland pozolânico (CP IV - 32) e adotam-se com frequência os traços de dosagem 1:1:6 e 1:2:9 (cimento:cal hidráulica:areia), em volume.

Em relação às propriedades das argamassas obtidas em algumas pesquisas, verificou-se que o aumento do teor de resíduo de areia de fundição em substituição ao agregado natural resultou em aumento da fluidez da argamassa (KRUGER; 
CABRAL; SOUZA, 2013; TOLEDO et al., 2013; MIGUEL et al., 2015) e queda de resistência à compressão (KRUGER; CABRAL; SOUZA, 2013; TOLEDO et al., 2013; KHANDURI, 2010; SWAPNA; PATIL, 2015).

Outro aspecto verificado nos trabalhos em argamassa na literatura é que a maioria deles não utiliza a cal como aglomerante nas argamassas, com exceção do estudo realizado por Miguel et al. (2015), que verificou viabilidade técnica de aplicação do resíduo de areia de fundição em argamassa de revestimentos trabalháveis. A cal é um produto cuja elevada área específica auxilia no comportamento no estado fresco (reologia e retenção de água) das argamassas (CINCOTTO; QUARCIONI; JOHN, 2007). Guimarães (2002) destaca que a propriedade da plasticidade que a cal confere às argamassas no estado fresco facilita o espalhamento sem separação da água ou segregação do material sólido, evitando, assim, fissuração do material.

Em Criciúma, local da realização desta pesquisa, a cal utilizada nas argamassas de revestimento é um produto comercialmente vendido por "cal hidráulica”. Segundo Cincotto, Quarcioni e John (2007), a cal hidráulica recebe essa designação por conter compostos hidráulicos e cal hidratada ou as misturas de cal com pozolanas ou escória de altoforno. Possivelmente essa segunda descrição é a cal comercializada em Criciúma, pois, segundo o fabricante, é uma mistura de cinza mineral, óxido de cálcio e óxido de magnésio, o que é verificado nesta pesquisa. Existem poucos estudos a respeito desse tipo cal hidráulica juntamente com resíduo de areia de fundição em argamassas.

Diante do exposto, este trabalho teve como objetivo caracterizar o resíduo de areia de fundição fenólica e dosar e avaliar argamassas trabalháveis produzidas com esse resíduo no estado fresco e no estado endurecido. Também foi avaliada a toxicidade das argamassas produzidas com e sem o resíduo de areia de fundição, assim como do próprio resíduo.

\section{Materiais e métodos}

Este estudo foi desenvolvido em duas etapas. $\mathrm{Na}$ primeira foi realizada a caracterização dos agregados miúdos utilizados: um resíduo de areia de fundição e uma areia natural comumente utilizada na região para argamassas de revestimento. Já na segunda etapa foram feitas a caracterização dos materiais utilizados nas argamassas e a avaliação das propriedades das argamassas sem e com substituição da areia natural pelo resíduo de areia de fundição. A seguir são descritos detalhadamente os materiais e métodos de cada etapa.

\section{Caracterização dos agregados miúdos utilizados}

Nesta primeira etapa foram caracterizados dois agregados miúdos que seriam utilizados nas argamassas de revestimento. Assim, foi selecionada uma areia natural comumente utilizada na região para esse fim e um resíduo de areia de fundição fenólica.

O resíduo foi obtido do descarte da areia de moldagem que era utilizada na produção de moldes para o vazamento de metal líquido e a obtenção de peças metálicas. A areia de moldagem é um sistema constituído essencialmente de areia, um ou mais aglomerantes e aditivos. No caso da areia em estudo se utilizava um aglomerante sintético, que era uma resina fenólica, para a obtenção de moldes mais resistentes. A areia utilizada na moldagem pode ser recuperada e reutilizada, contudo existe um limite. Assim, o resíduo de areia de fundição coletado era material de descarte e ficava depositado em uma pilha no interior da empresa, que seria enviado para empresas terceirizadas e depositado em aterros industriais. A amostra coletada do resíduo de areia de fundição, aproximadamente $150 \mathrm{~kg}$, foi retirada de vários pontos dessa pilha.

Esse resíduo de areia de fundição fica com uma tonalidade escura (preta) e com uma quantidade de impurezas de tamanhos variados de resíduo da própria fundição (pedaços do molde que não se desagregam totalmente - torrões/grumos - e metais provenientes de restos/rebarbas das peças fabricadas). Então, para ser utilizado como agregado miúdo em argamassas, foi necessário fazer um tratamento inicial, ou seja, peneirar o resíduo na peneira de abertura de $4,75 \mathrm{~mm}$, sendo então utilizado o material passante nessa peneira. Nesse procedimento foi determinado o teor de impurezas encontradas nessa amostra. Após o peneiramento foram realizados os ensaios de caracterização.

Já a areia natural, proveniente de leito de rio, foi obtida comercialmente, como uma areia média lavada, de um fornecedor local que entrega para várias construtoras.

As amostras obtidas do resíduo de areia de fundição e da areia natural foram caracterizadas nas seguintes propriedades: composição granulométrica (NBR NM 248 (ABNT, 2003a)), massa específica aparente (NBR NM 52 (ABNT, 2009a)), massa unitária (NBR NM 45 (ABNT, 2006)), teor de material pulverulento (NBR NM 46 (ABNT, 2003b)), perda ao fogo e análise química quantitativa (espectrometria de fluorescência de raios $\mathrm{X}$ realizada no Laboratório de Pesquisa e Inovação Tecnológica da empresa Colorminas). 
Também para a amostra de resíduo de areia de fundição foram realizados ensaios de caracterização e de classificação de resíduos sólidos de acordo com a norma NBR 10004 (ABNT, 2004), como classificação físico-química, corrosividade, reatividade, ensaio de lixiviação e de solubilização. Este ensaio foi realizado no Instituto de Pesquisas Ambientais e Tecnológicas (IPAT) da Universidade do Extremo Sul Catarinense (UNESC), no Laboratório de Resíduos Sólidos.

\section{Segunda etapa: avaliação das propriedades das argamassas com os agregados estudados}

A avaliação das propriedades das argamassas com os agregados utilizados foi realizada em argamassas mistas (cimento e cal), por ser utilizada para revestimento na região. O cimento utilizado foi um cimento Portland pozolânico (CP IV-32), disponível na região, sendo suas características físicas, químicas e mecânicas fornecidas pelo fabricante (Tabela 1). Foram realizados ensaios para a determinação da massa unitária (NBR NM 45 (ABNT, 2006)), perda ao fogo e análise química quantitativa (espectrometria de fluorescência de raios $\mathrm{X}$ realizada no Laboratório de Pesquisa e Inovação Tecnológica da empresa Colorminas), para complementar a caracterização do cimento utilizado.
A cal utilizada foi uma disponível na região denominada de cal hidráulica. A descrição do produto na sacaria é que ele é composto de cinzas, óxido de cálcio e óxido de magnésio. Assim, foram realizados ensaios de caracterização desse material, como massa específica (NBR NM 23 (ABNT, 2001)), massa unitária (NBR NM 45 (ABNT, 2006)), perda ao fogo e análise química quantitativa (espectrometria de fluorescência de raios $\mathrm{X}$ realizada no Laboratório de Pesquisa e Inovação Tecnológica da empresa Colorminas).

\section{Propriedades da argamassa no estado fresco}

Para avaliação das propriedades das argamassas, estipulou-se um traço de referência constantemente utilizado na região de Criciúma para argamassas de revestimento. $O$ traço estipulado foi de 1:1:6 (cimento, cal hidráulica e areia), em volume. Assim, foi avaliada uma argamassa de referência com esse traço e $100 \%$ de areia natural (agregado miúdo natural).

A partir do traço de referência foram confeccionadas três argamassas com resíduo de areia de fundição com teores de substituição, em volume, da areia natural de $10 \%$, 30\% e $100 \%$. Essas argamassas foram denominadas de argamassa $10 \%$ de areia de fundição, $30 \%$ de areia de fundição e $100 \%$ de areia de fundição, respectivamente.

Tabela 1 - Características do Cimento Portland Pozolânico - CP IV-32 utilizado

\begin{tabular}{|c|c|c|c|c|}
\hline \multicolumn{5}{|c|}{ Ensaios Físicos } \\
\hline Item de controle & Média & Desvio padrão & Mínimo & Máximo \\
\hline Material retido \#200 (mesh) (\%) & 0,22 & 0,10 & 0,11 & 0,50 \\
\hline Material retido \#325 (mesh) (\%) & 2,32 & 0,38 & 1,70 & 3,20 \\
\hline Blaine $\left(\mathrm{cm}^{2} / \mathrm{g}\right)$ & $4.414,40$ & 127,60 & $4.100,00$ & $4.610,00$ \\
\hline Água de consistência (\%) & 31,04 & 0,34 & 30,40 & 31,70 \\
\hline Início de pega (horas) & $04: 23$ & $00: 34$ & $04: 15$ & 05:33 \\
\hline Fim de pega (horas) & 05:38 & $00: 37$ & 04:25 & $06: 23$ \\
\hline Expansibilidade a quente (mm) & 0,00 & 0,00 & 0,00 & 0,00 \\
\hline Resistência aos 3 dias (MPa) & 21,99 & 0,71 & 20,50 & 23,50 \\
\hline Resistência aos 7 dias (MPa) & 26,96 & 1,07 & 25,10 & 28,90 \\
\hline Resistência aos 28 dias (MPa) & 37,06 & 1,01 & 35,40 & 37,90 \\
\hline Massa específica $\left(\mathrm{g} / \mathrm{cm}^{3}\right)$ & 2,78 & - & - & - \\
\hline \multicolumn{5}{|c|}{ Ensaios Químicos } \\
\hline Item de controle & Média & Desvio padrão & Mínimo & Máximo \\
\hline Perda ao fogo (\%) & 3,70 & 0,32 & 3,07 & 4,20 \\
\hline $\mathrm{MgO}(\%)$ & 4,59 & 0,19 & 4,20 & 4,97 \\
\hline $\mathrm{SO}_{3}(\%)$ & 2,52 & 0,12 & 2,20 & 2,73 \\
\hline Resíduo insolúvel (\%) & 31,54 & 1,20 & 28,66 & 33,46 \\
\hline
\end{tabular}

Fonte: dados fornecidos pelo fabricante do cimento Portland. 
Primeiramente foram misturados os materiais secos (cimento Portland, cal hidráulica e agregado miúdo), e depois foi adicionada água aos poucos até obter-se uma mistura homogênea e trabalhável para argamassa de revestimento. Assim, a quantidade de água utilizada para cada argamassa foi aquela necessária para obter um índice de consistência (flow table - mesa de consistência) de $255 \pm 10 \mathrm{~mm}$ que foi considerada trabalhável por um pedreiro experiente para a argamassa de referência. O índice de consistência (flow table) foi realizado segundo as recomendações da NBR 13276 (ABNT, 2005a).

Na Figura 1 é possível visualizar a composição das argamassas no estado fresco em relação à distribuição quantitativa de constituintes nas argamassas em volume específico.

Após a obtenção do índice de consistência estipulado, foram realizados os ensaios de caracterização das propriedades no estado fresco, como retenção de água (conforme NBR 13277 (ABNT, 2005b)) teor de ar incorporado e densidade de massa (conforme a NBR 13278 (ABNT, 2005c)).

Em seguida foram moldados os corpos de prova para os ensaios das propriedades no estado endurecido. As propriedades do estado endurecido avaliadas foram resistência à tração na flexão (NBR 13279 (ABNT, 2005d)), resistência à compressão (NBR 13279 (ABNT, 2005d)), densidade de massa aparente no estado endurecido (NBR 13280 (ABNT, ABNT, 2005e)) e módulo de elasticidade (NBR 15630 (ABNT, 2009b)) (com o uso de aparelho do fabricante Pundit). Todas as propriedades do estado endurecido foram avaliadas aos 28 dias, e os corpos de prova foram curados ao ar até a data de realização dos ensaios. Os dados obtidos foram submetidos a uma análise estatística (análise de variância e ao teste de separação de médias de Duncan ao nível de 5\% de probabilidade de erro).

Após a determinação da resistência à compressão, os corpos de prova foram moídos e enviados para o Ipat/Unesc, no Laboratório de Resíduos Sólidos, para a caracterização e classificação de resíduos sólidos de acordo com a norma NBR 10004 (ABNT, 2004), como classificação físico-química, corrosividade, reatividade, ensaio de lixiviação e de solubilização.

\section{Resultados e discussão}

A seguir são apresentados os resultados obtidos na primeira e segunda etapa deste trabalho e realizada a discussão dos resultados.

\section{Primeira etapa: caracterização dos agregados miúdos utilizados}

Primeiramente foi feito um tratamento inicial no resíduo de areia de fundição para ser utilizado como agregado miúdo em argamassas de revestimento. Na Tabela 2 são apresentados os valores obtidos desse tratamento, como massa total de amostra coletada, material passante e retido na peneira de $4,75 \mathrm{~mm}$, e teor de impurezas na amostra. No momento da coleta da amostra ela se encontrava seca ao ar (protegida contra intempéries), tendo sido, em seguida, realizado o peneiramento.

Observa-se na Tabela 2 que o teor de impurezas encontrado na amostra foi de 7,54\%. A grande maioria das impurezas era resíduo de ferro fundido, provavelmente do excesso/rebarba das peças que haviam sido produzidas nos moldes utilizando essa areia. O peneiramento foi considerado fácil de ser executado, pois o resíduo de areia de fundição era fino (Figura 2) e os grãos passavam pela peneira estipulada (abertura de 4,75 mm), comportamento que pode ser observado na Tabela 3 , em que o diâmetro máximo característico da amostra é de $0,60 \mathrm{~mm}$.

Com as amostras obtidas do resíduo de areia de fundição (após o tratamento inicial) e da areia natural, foi realizada a distribuição granulométrica (Figura 2). Também é representada na Figura 2 a distribuição granulométrica da composição dos agregados miúdos com $10 \%$ de resíduo de areia de fundição mais $90 \%$ de areia natural e com 30\% de resíduo de areia de fundição mais $70 \%$ de areia natural.

Observa-se na Figura 2 que os dois agregados são de granulometrias distintas, sendo que a areia natural contém grãos de maiores diâmetros do que o resíduo de areia de fundição. O resíduo de areia de fundição poderia ser considerado uma areia fina. Nota-se na Figura 2 que tanto os agregados miúdos quanto as misturas dos dois agregados apresentam um perfil granulométrico contínuo. No entanto, o resíduo de areia de fundição (100\% areia de fundição) não contém grãos com dimensão superior de $0,60 \mathrm{~mm}$. A diferença entre a composição granulométrica das areias também pode ser verificada pelos parâmetros obtidos neste ensaio, como dimensão máxima e mínima característica da amostra e módulo de finura (Tabela 3). Na Tabela 3 também são apresentados os valores obtidos de massa específica aparente, massa unitária e material pulverulento. 
Figura 1 - Distribuição quantitativa de constituintes nas argamassas, em volume específico

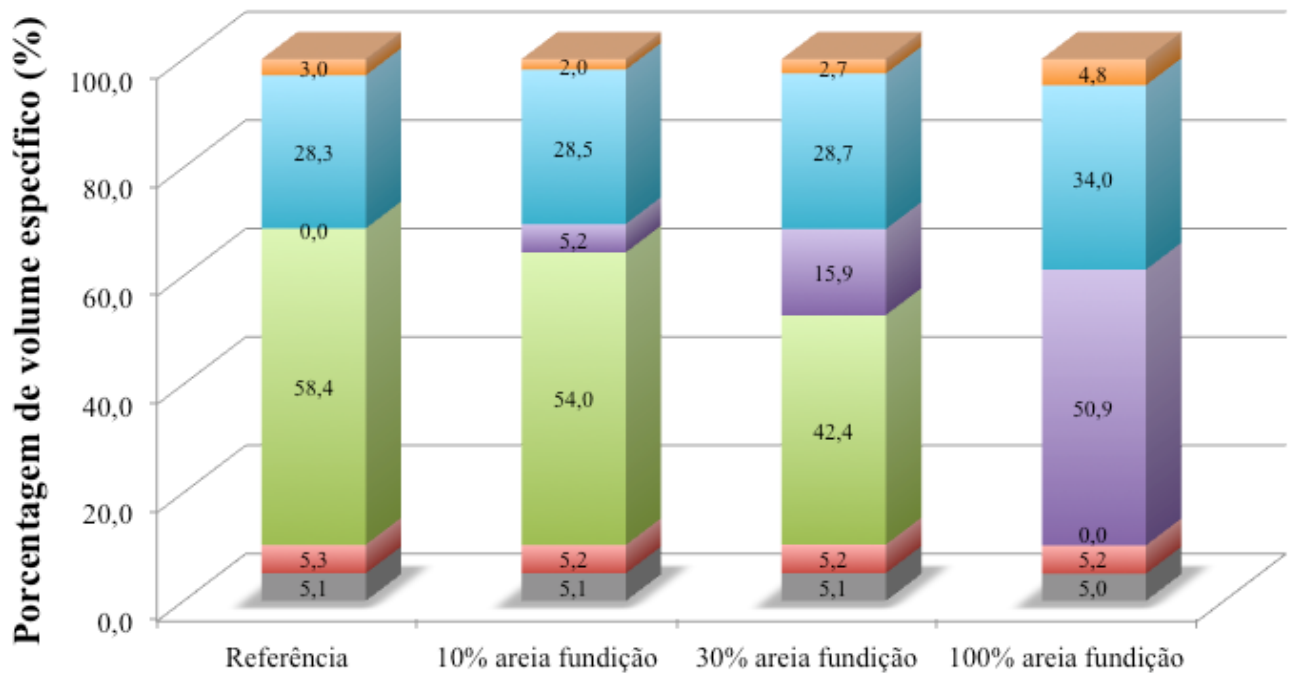

Argamassa

"Cimento $=$ Cal $=$ Areia Natural $=$ Areia de Fundição $=$ Água $=$ Ar

Tabela 2 - Massa total da amostra coletada, material passante e retido na peneira 4,75mm e o teor de impurezas na amostra

\begin{tabular}{c|c|c|c|c}
\hline Agregado & $\begin{array}{c}\text { Massa total } \\
\text { da amostra } \\
\mathbf{( k g )}\end{array}$ & $\begin{array}{c}\text { Massa de material } \\
\text { passante } \\
\mathbf{( k g )}\end{array}$ & $\begin{array}{c}\text { Massa de material } \\
\text { retido } \\
\mathbf{( k g )}\end{array}$ & $\begin{array}{c}\text { Impurezas na } \\
\text { amostra } \\
\mathbf{( \% )}\end{array}$ \\
\hline Areia de fundição & 145,51 & 134,54 & 10,97 & 7,54 \\
\hline
\end{tabular}

Figura 2 - Distribuição granulométrica da areia natural e da areia de fundição

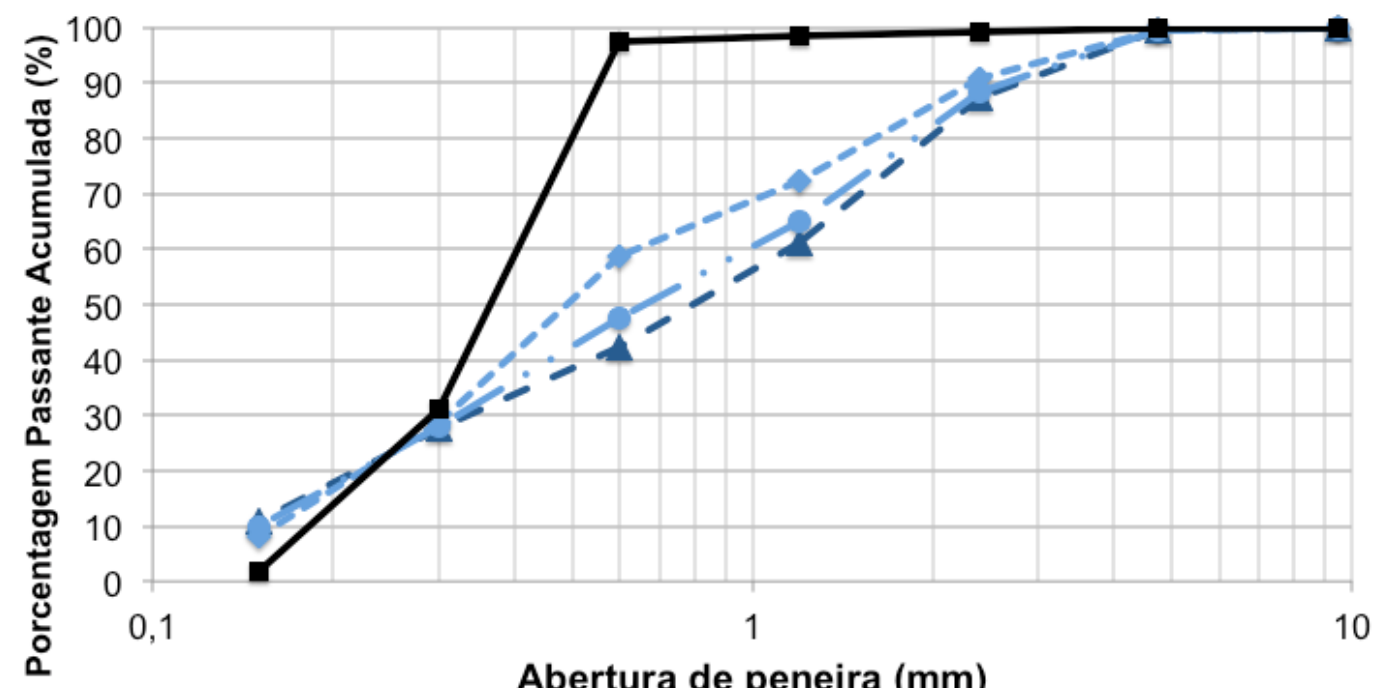

Abertura de peneira $(\mathrm{mm})$

- $100 \%$ Areia Natural

$\checkmark 30 \%$ Areia de Fundição
$-10 \%$ Areia de Fundição

$-\mathbf{- 1 0 0 \%}$ Areia de Fundição 
Observa-se na Tabela 3 que o módulo de finura da areia natural é superior àquele obtido para o resíduo de areia de fundição. Também se verifica com dados obtidos na Tabela 3 que as duas areias apresentam massa específica aparente muito semelhantes. No entanto, a massa unitária da areia natural é superior àquela obtida para o resíduo de areia de fundição. Verificou-se ainda que a quantidade de material pulverulento para a areia natural é superior àquela obtida para o resíduo de areia de fundição.

A Tabela 4 apresenta os valores de perda ao fogo e a análise química quantitativa pela espectrometria de fluorescência de raios $X$.

Como pode ser observado na Tabela 4, o resíduo de areia de fundição apresentou um teor de sílica $\left(\mathrm{SiO}_{2}\right)$ ligeiramente superior àquele observado na areia natural (diferença de 3,40\%). Além disso, o resíduo de areia de fundição apresentou teores menores de $\mathrm{Al}_{2} \mathrm{O}_{3}$ e de $\mathrm{Fe}_{2} \mathrm{O}_{3}$ do que a areia natural.

Em relação à perda ao fogo, o resíduo de areia de fundição apresentou uma porcentagem maior do que aquela verificada na areia natural, possivelmente por conter algum componente volátil, como a resina fenólica a essa temperatura.

A Tabela 5 apresenta as características físico- químicas do resíduo de areia de fundição.

A Tabela 6 e a Tabela 7 apresentam os resultados dos ensaios de corrosividade e reatividade para o resíduo de areia de fundição.

A partir do valor apresentado na Tabela 6, o resíduo de areia de fundição é caracterizado como não corrosivo, pois apresenta pH igual a 10,02, o que não ultrapassa o limite estabelecido pela norma. Segundo a norma NBR 10004 (ABNT, 2004), em relação à reatividade, o resíduo ensaiado é caracterizado como não reativo, pois não apresenta em sua constituição íons cianeto e sulfeto acima dos limites estabelecidos pela norma (Tabela 7). Portanto, o resíduo é classificado como não perigoso tanto pelo ensaio de corrosividade quanto pelo de reatividade pela norma NBR 10004 (ABNT, 2004).

A Tabela 8 apresenta o resultado do ensaio de lixiviação do resíduo de areia de fundição.

Como pode ser verificado na Tabela 8, os parâmetros analisados não apresentam concentrações acima dos limites máximos permitidos pela NBR 10004 (ABNT, 2004), caracterizando o resíduo como não tóxico, sendo classificado como não perigoso - Classe II.

Tabela 3 - Resultados obtidos da caracterização dos agregados estudados

\begin{tabular}{|c|c|c|c|c|c|c|}
\hline Agregado & $\begin{array}{c}\text { Dimensão } \\
\text { máxima } \\
\text { característica da } \\
\text { amostra }(\mathbf{m m})\end{array}$ & $\begin{array}{c}\text { Dimensão } \\
\text { mínima } \\
\text { característica da } \\
\text { amostra }(\mathbf{m m})\end{array}$ & $\begin{array}{l}\text { Módulo } \\
\text { de } \\
\text { finura }\end{array}$ & $\begin{array}{c}\text { Massa } \\
\text { específica } \\
\text { aparente } \\
\left(\mathrm{g} / \mathrm{cm}^{3}\right)\end{array}$ & $\begin{array}{c}\text { Massa } \\
\text { unitária } \\
\left(\mathbf{g} / \mathbf{c m}^{3}\right)\end{array}$ & $\begin{array}{c}\text { Material } \\
\text { pulverulento } \\
(\%)\end{array}$ \\
\hline $\begin{array}{l}\text { Areia } \\
\text { natural }\end{array}$ & 4,75 & 0,15 & 2,71 & 2,61 & 1,55 & 5,40 \\
\hline $\begin{array}{l}\text { Areia de } \\
\text { fundição }\end{array}$ & 0,60 & $<0,15$ & 1,72 & 2,62 & 1,36 & 1,78 \\
\hline
\end{tabular}

Tabela 4 - Análise química quantitativa e perda ao fogo do resíduo de areia de fundição

\begin{tabular}{|c|c|c|}
\hline Análise Química & Areia Natural & Areia de Fundição \\
\hline Composto & Quantidade (\%) & Quantidade (\%) \\
\hline $\mathrm{SiO}_{2}$ & 91,90 & 95,29 \\
\hline $\mathrm{Al}_{2} \mathrm{O}_{3}$ & 3,56 & 2,08 \\
\hline $\mathrm{Fe}_{2} \mathrm{O}_{3}$ & 1,01 & 0,38 \\
\hline $\mathrm{CaO}$ & 0,11 & 0,11 \\
\hline $\mathrm{K}_{2} \mathrm{O}$ & 0,97 & 0,11 \\
\hline MgO & 0,17 & 0,17 \\
\hline $\mathrm{Na}_{2} \mathrm{O}$ & 0,24 & 0,37 \\
\hline $\mathrm{P}_{2} \mathrm{O}_{5}$ & 0,20 & - \\
\hline $\mathrm{TiO}_{2}$ & 1,16 & 0,05 \\
\hline Perda ao Fogo (P.F.) & 0,62 & 1,30 \\
\hline
\end{tabular}


Tabela 5 - Características físico-químicas do resíduo de areia de fundição

\begin{tabular}{l|l}
\hline \multicolumn{1}{c|}{ Característica } & \multicolumn{1}{c}{ Classificação } \\
\hline Aspecto & Sólido (pó) \\
Coloração & Preta \\
Odor & Inodoro \\
Umidade a $105^{\circ} \mathrm{C}(\%)$ & 0,40 \\
Líquidos livres & Ausentes (método de acordo com a norma NBR 12988 (ABNT, 1993) \\
\hline & \\
Foto do resíduo & \\
\hline
\end{tabular}

Tabela 6 - Corrosividade do resíduo de areia de fundição

Nota: "L.Q. - Limite de quantificação.

\begin{tabular}{c|c|c|c|c}
\hline Parâmetro & Unidade & Resultado & Valor recomendado & L.Q. $^{++}$ \\
\hline pH em água (1:1) & - & 10,02 & 2 a 12,4 & 0,01 \\
\hline
\end{tabular}

Tabela 7 - Reatividade do resíduo de areia de fundição

\begin{tabular}{l|c|c|c|c}
\hline \multicolumn{1}{c|}{ Parâmetro } & Unidade & Resultado & Limite liberável por kg de resíduo & L.Q. $^{++}$ \\
\hline Ácido cianídrico $(\mathrm{HCN})$ & $\mathrm{mg} / \mathrm{kg}$ & $<0,05$ & $250 \mathrm{mg} \mathrm{de} \mathrm{HCN}$ & 0,05 \\
Ácido sulfídrico $\left(\mathrm{H}_{2} \mathrm{~S}\right)$ & $\mathrm{mg} / \mathrm{kg}$ & $<40$ & $500 \mathrm{mg} \mathrm{de} \mathrm{H}_{2} \mathrm{~S}$ & 40 \\
\hline
\end{tabular}

Nota: +'L.Q. - Limite de quantificação.

Tabela 8 - Resultado do ensaio de lixiviação do resíduo de areia de fundição

\begin{tabular}{l|c|c|c}
\hline \multicolumn{1}{c|}{ Parâmetro } & $\begin{array}{c}\text { Resultados } \\
(\mathbf{m g} / \mathbf{L})\end{array}$ & $\begin{array}{c}\text { Valor máximo permitido NBR } \\
\mathbf{1 0 0 0 4}(\mathbf{A B N T}, \mathbf{2 0 0 4})(\mathbf{m g} / \mathbf{L})\end{array}$ & L.Q. $^{++}$ \\
\hline Arsênio & $<0,01$ & 1,0 & 0,01 \\
Bário & 0,1 & 70,0 & 0,01 \\
Cádmio & $<0,005$ & 0,5 & 0,005 \\
Chumbo & $<0,01$ & 1,0 & 0,01 \\
Cromo total & 0,02 & 5,0 & 0,01 \\
Fenóis totais & 0,11 & 1,0 & 0,05 \\
Fluoreto & 0,2 & 150,0 & 0,1 \\
Mercúrio & $<0,001$ & 0,1 & 0,001 \\
Prata & $<0,01$ & 5,0 & 0,01 \\
Selênio & $<0,01$ & 1,0 & 0,01 \\
\hline
\end{tabular}

Nota: "L.Q. - Limite de quantificação.

A Tabela 9 apresenta o resultado do ensaio de solubilização do resíduo de areia de fundição.

Nota-se na Tabela 9 que dos parâmetros analisados de alumínio, ferro, fenóis totais, fluoretos e sódio apresentam concentrações superiores ao padrão para o ensaio de solubilização, caracterizando o resíduo como não inerte nesses ensaios (indicado em negrito na Tabela 9). Assim, como o resíduo é contaminado com resinas fenólicas e metais, pode ocorrer sua solubilização em água e atingir os lençóis freáticos nos aterros industriais, ocorrendo um impacto ambiental. 
Tabela 9 - Resultado do ensaio de solubilização do resíduo de areia de fundição

\begin{tabular}{l|c|c|c}
\hline \multicolumn{1}{c|}{ Parâmetro } & $\begin{array}{c}\text { Resultados } \\
(\mathbf{m g} / \mathbf{L})\end{array}$ & $\begin{array}{c}\text { Valor máximo permitido NBR 10004 } \\
\text { (ABNT, 2004) (mg/L) }\end{array}$ & L.Q. $^{++}$ \\
\hline Alumínio & $\mathbf{1 , 4}$ & $\mathbf{0 , 2}$ & $\mathbf{0 , 1}$ \\
Arsênio & $<0,01$ & 0,01 & 0,01 \\
Bário & 0,02 & 0,7 & 0,1 \\
Cádmio & $<0,005$ & 0,005 & 0,005 \\
Chumbo & $<0,01$ & 0,01 & 0,01 \\
Cloreto & 7 & 250,0 & 5 \\
Cobre & 0,030 & 2,0 & 0,005 \\
Cromo total & $<0,01$ & 0,05 & 0,01 \\
Fenóis totais & $\mathbf{0 , 0 3}$ & $\mathbf{0 , 0 1}$ & $\mathbf{0 , 0 1}$ \\
Ferro & $\mathbf{1 , 6 2}$ & $\mathbf{0 , 3}$ & $\mathbf{0 , 0 5}$ \\
Fluoreto & $\mathbf{8 , 5}$ & $\mathbf{1 , 5}$ & $\mathbf{0 , 1}$ \\
Manganês & 0,10 & 0,1 & 0,01 \\
Mercúrio & $<0,001$ & 0,001 & 0,001 \\
Nitrato (expresso em $\mathrm{N}^{+}$ & $<0,1$ & 10,0 & 0,1 \\
Prata & $<0,01$ & 0,05 & 0,01 \\
Selênio & $<0,01$ & 0,01 & 0,01 \\
Sódio & $\mathbf{2 9 9 , 5 8}$ & $\mathbf{2 0 0 , 0}$ & $\mathbf{0 , 0 1}$ \\
Sulfatos (expresso em $\mathrm{SO}_{4}$ ) & 10,25 & 250,0 & 5 \\
Surfactantes & $<0,5$ & 0,5 & 0,5 \\
Zinco & 0,06 & 5,0 & 0,01 \\
\hline
\end{tabular}

Nota: +' L.Q. - Limite de quantificação.

O estudo realizado por Scheunemann (2005), com resíduo de areia de fundição fenólica, mostra que no ensaio de solubilização somente os teores de ferro estavam acima do estabelecido pela NBR 10004 (ABNT, 2004). Essa diferença nos resultados dos resíduos demonstra a importância da realização desse ensaio para a caracterização dos resíduos de areia de fundição utilizada na pesquisa.

Considerando os resultados obtidos de lixiviação (Tabela 8) e de solubilização (Tabela 9), e as características físico-químicas (Tabela 5), o resíduo de areia de fundição estudado foi classificado como resíduo não perigoso - Classe II A - não inerte, segundo a NBR 10004 (ABNT, 2004), nos parâmetros analisados. Esses resultados podem ser modificados quando o resíduo for incorporado em matrizes cimentícias, pois pode reagir ou ser encapsulado pelos elementos de hidratação dos aglomerantes, como será abordado na segunda etapa.

\section{Segunda etapa: avaliação das propriedades das argamassas com os agregados estudados}

Primeiramente são apresentados os resultados obtidos das características químicas e físicas do cimento Portland pozolânico (CP IV) e da cal hidráulica (Tabela 10).

Observa-se na Tabela 10 que, conforme era esperado, os maiores teores obtidos foram de óxido de Cálcio (CaO), sílica $\left(\mathrm{SiO}_{2}\right)$ e alumínio $\left(\mathrm{Al}_{2} \mathrm{O}_{3}\right)$ para o cimento Portland. Já para a cal hidráulica os maiores teores obtidos foram de sílica $\left(\mathrm{SiO}_{2}\right)$, proveniente possivelmente da cinza volante, e de óxido de cálcio $(\mathrm{CaO})$ e de óxido de magnésio (MgO). Os resultados deste ensaio, juntamente com o resultado de perda ao fogo, mostram possivelmente a presença de hidróxido de cálcio e hidróxido de magnésio, que podem promover maior retenção de água e plasticidade às argamassas, assim como observado com a cal hidratada.

A seguir são apresentados os resultados obtidos das propriedades dos estados fresco e endurecido das argamassas estudadas.

\section{Propriedades no estado fresco das argamassas}

As propriedades do estado fresco obtidas como o índice de consistência (flow table), a densidade de massa, o teor de ar incorporado e a retenção de água constam na Tabela 11. Além disso, a Tabela 11 apresenta a relação água-materiais secos observada nas argamassas para obter um índice de consistência (flow table) de $255 \pm 10 \mathrm{~mm}$.

Observa-se na Tabela 11 que se obtiveram valores de índice de consistência (flow table) conforme preestabelecido. Para a argamassa de referência e as argamassas com $10 \%$ e $30 \%$ de areia de fundição, praticamente se manteve constante a relação águamateriais secos. No entanto, para a argamassa com 
$100 \%$ de areia de fundição houve aumento de 35\% dessa relação. Esse comportamento já era esperado, pois o resíduo de areia de fundição era mais fino do que a areia natural (Figura 2 e Tabela 3), demandando uma quantidade de água maior para obter a mesma consistência.

Em relação ao teor de ar incorporado, verificou-se um pequeno aumento, pois se situou entre $2 \%$ e $5 \%$ conforme aumentou a substituição do resíduo de areia de fundição. Esse aumento pode ter ocorido pela existência do fenol proveniente do resíduo de areia de fundição (Tabela 9), uma vez que, segundo Dolch (1984), alguns aditivos incorporadores de ar à base de sais de madeira contêm fenol.

Quanto à retenção de água, a argamassa que apresentou o maior valor de retenção foi a argamassa de referência. Em relação às argamassas com resíduo de areia de fundição, conforme se aumentou o teor de substituição do resíduo, a retenção de água aumentou, com exceção da argamassa com $100 \%$ de areia de fundição, que apresentou valores ligeiramente inferiores aos da argamassa com 30\% de areia de fundição.

\section{Propriedades no estado endurecido das argamassas}

Na Figura 3 são apresentados os valores obtidos de resistência à compressão e resistência à tração na flexão, com o desvio padrão das argamassas estudadas.

Nota-se na Figura 3 que houve influência do teor de resíduo de areia de fundição nas resistências. Conforme aumentou o teor de substituição da areia natural pelo resíduo de areia de fundição, ocorreu diminuição dos valores de resistências em relação à argamassa de referência (areia natural). Após análise estatística ${ }^{1}$, verificou-se que não houve diferença significativa entre os valores obtidos dos corpos de prova das argamassas com $10 \%$ e $30 \%$ de areia de substituição. No entanto, houve diferença significativa dessas argamassas (10\% e 30\% de areia de fundição) para a argamassa de referência e para a argamassa com $100 \%$ de areia de fundição.

Tabela 10 - Características físicas e químicas do cimento Portland e da cal hidráulica

\begin{tabular}{|c|c|c|}
\hline Análise química & Cimento Portland & Cal hidráulica \\
\hline Composto & Quantidade (\%) & Quantidade (\%) \\
\hline $\mathrm{SiO}_{2}$ & 31,15 & 30,18 \\
\hline $\mathrm{Al}_{2} \mathrm{O}_{3}$ & 9,03 & 8,09 \\
\hline $\mathrm{Fe}_{2} \mathrm{O}_{3}$ & 2,66 & 2,44 \\
\hline $\mathrm{CaO}$ & 45,51 & 22,95 \\
\hline $\mathrm{K}_{2} \mathrm{O}$ & 1,43 & 0,93 \\
\hline $\mathrm{MgO}$ & 3,74 & 14,64 \\
\hline $\mathrm{P}_{2} \mathrm{O}_{5}$ & 0,18 & 0,10 \\
\hline $\mathrm{TiO}_{2}$ & 0,34 & 0,29 \\
\hline Perda ao fogo (P. F.) & 2,51 & 20,74 \\
\hline Análise física & Cimento Portland & Cal hidráulica \\
\hline Massa específica (NBR NM 23, ABNT, 2001) & $2,78 \mathrm{~g} / \mathrm{cm}^{3 *}$ & $2,43 \mathrm{~g} / \mathrm{cm}^{3}$ \\
\hline Massa unitária (NBR NM 45, ABNT, 2006) & $0,84 \mathrm{~g} / \mathrm{cm}^{3}$ & $0,75 \mathrm{~g} / \mathrm{cm}^{3}$ \\
\hline
\end{tabular}

Tabela 11 - Quantidade de material utilizado nas argamassas

\begin{tabular}{lccccc}
\hline \multicolumn{1}{c}{ Argamassa } & $\begin{array}{c}\mathbf{H}^{*} \\
\mathbf{( \% )}\end{array}$ & $\begin{array}{c}\text { Índice de } \\
\text { consistência } \\
\mathbf{( m m )}\end{array}$ & $\begin{array}{c}\text { Densidade } \\
\mathbf{d e ~ m a s s a} \\
\mathbf{( g / \mathbf { c m } ^ { 3 } )}\end{array}$ & $\begin{array}{c}\text { Teor de ar } \\
\text { incorporado } \\
\mathbf{( \% )}\end{array}$ & $\begin{array}{c}\text { Retenção de } \\
\text { água } \\
\mathbf{( \% )}\end{array}$ \\
\hline Referência & 15,8 & 249,04 & 2,08 & 3,00 & 86 \\
10\% de Areia de fundição & 15,7 & 261,39 & 2,10 & 1,97 & 71 \\
30\% de Areia de fundição & 16,0 & 249,97 & 2,08 & 2,69 & 80 \\
100\% de Areia de fundição & 21,3 & 255,05 & 1,94 & 4,84 & 77 \\
\hline
\end{tabular}

Nota: *relação água-materiais secos.

${ }^{1}$ Os dados de resistência foram submetidos à análise de variância

e ao teste de separação de médias de Duncan ao nível de $5 \%$ de probabilidade de erro. 
Figura 3 - Resistência à compressão e resistência à tração na flexão das argamassas

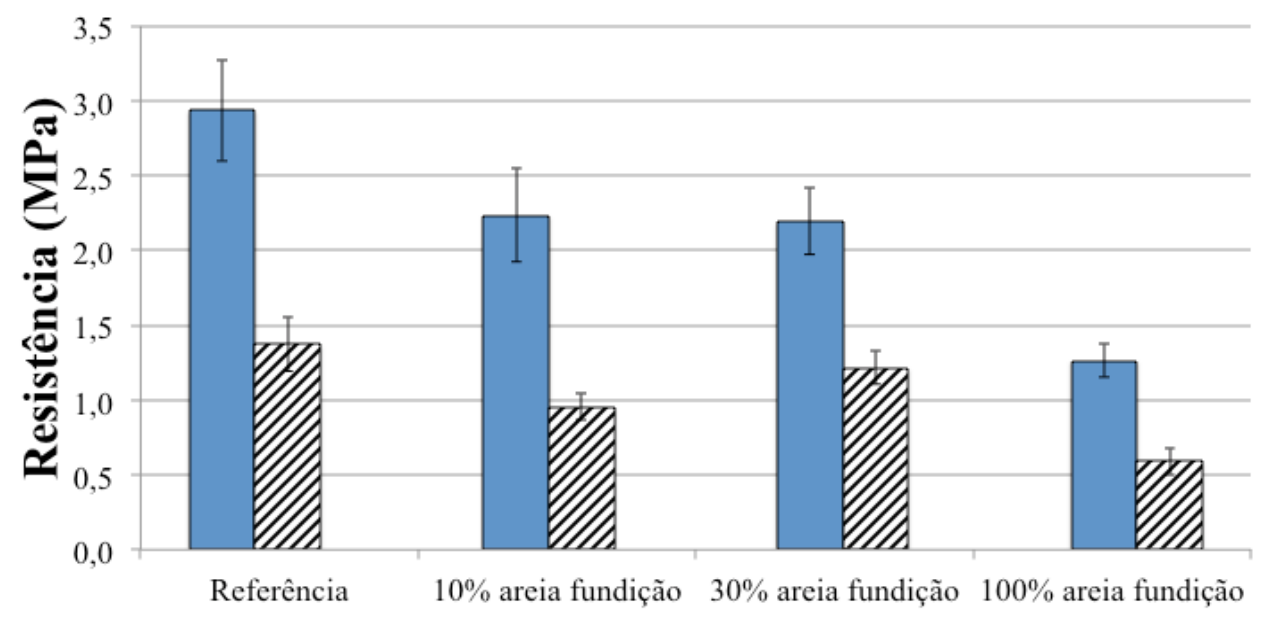

Argamassa

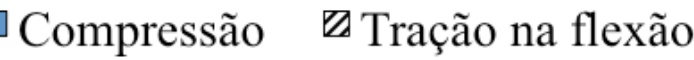

Para as argamassas com $10 \%$ e $30 \%$ de areia de fundição ocorreu a diminuição (na média de 24,5\%) dos valores de resistência à compressão, mesmo sendo semelhante a relação água-materiais secos (Tabela 10) para obter o índice de consistência desejado no estado fresco. Essa redução nos valores pode ter ocorrido pela redução da aderência entre a pasta e o agregado, visto que o resíduo de areia de fundição contém resina fenólica, que pode estar aderida nos grãos. Outra possibilidade seria o aumento da área de transição pasta-agregado, resultando em um aumento de vazios e na formação de grandes cristais de $\mathrm{Ca}(\mathrm{OH})_{2}$, o que diminui a resistência mecânica, segundo o verificado por Watanabe (2004). Conforme descrito pelo fabricante e de acordo com a composição da cal hidráulica (Tabela 10), a cal hidráulica utilizada nesta pesquisa é uma mistura de cinza e cal hidratada. A redução dos valores para as argamassas com $10 \%$ e $30 \%$ de areia de fundição também pode ter ocorrido pela redução dos valores de densidade de massa no estado endurecido, o que é apresentado na Tabela 12 e discutido a seguir.

Já para a argamassa com 100\% de areia de fundição, os valores de resistência à compressão foram $57 \%$ menores daqueles obtidos para a argamassa de referência (nesse caso foi verificada diferença significativa entre os valores obtidos). Essa redução maior nos valores de resistência pode ter ocorrido por dois fatores; o primeiro, como mencionado anteriormente, pela redução da aderência entre pasta e agregado miúdo ou do aumento da área de transição pasta-agregado; e o segundo pelo aumento de $135 \%$ na relação água-materiais secos em relação à argamassa de referência para obter o índice de consistência desejado. Essa hipótese se justifica no fato de o resíduo de areia de fundição ser mais fino (Figura 1 e Tabela 6), demandando uma quantidade de água maior para a mesma trabalhabilidade.

Os valores de resistência à tração obtidos também foram influenciados pelo teor de substituição do resíduo de areia de fundição. Após análise estatística, verificou-se que existe diferença significativa entre a argamassa de referência e as argamassas com $10 \%$ e $100 \%$ de areia de fundição. No entanto, pelos valores obtidos não houve diferença significativa entre a argamassa de referência e a argamassa com 30\% de areia de fundição.

Os valores obtidos da massa aparente no estado endurecido e módulo de elasticidade, assim como o coeficiente de variação, são apresentados na Tabela 12.

Observa-se na Tabela 14 que os valores obtidos de densidade de massa aparente no estado endurecido foram influenciados pelo teor de substituição do resíduo. Além disso, houve diferença significativa entre a argamassa de referência e as argamassas com $30 \%$ de areia de fundição e $100 \%$ de areia de fundição. Conforme aumentou o teor do resíduo de areia de fundição, verificou-se diminuição na densidade de massa aparente no estado endurecido e no módulo de elasticidade.

Os valores de módulo de elasticidade apresentaram comportamento semelhante aos valores obtidos de resistência à compressão (não houve diferença significativa entre os valores obtidos da argamassa com $10 \%$ e $30 \%$ de areia de fundição). Além disso, foi verificada correlação significativa entre os valores médios dessas propriedades (Figura 4a) 
(regressão significativa ao nível de $1 \%$ de probabilidade de erro) e entre os valores médios da densidade de massas e da resistência à compressão (Figura 4b) (regressão significativa ao nível de 5\% de probabilidade de erro). Considerando a mesma tensão, quanto maior o módulo de elasticidade, menor a deformabilidade da argamassa.

A Tabela 13 apresenta as características físicoquímicas das argamassas estudadas.

As Tabelas 14 e 15 apresentam os resultados dos ensaios de corrosividade e reatividade das argamassas estudadas.

Conforme os valores apresentados na Tabela 14, as argamassas estudadas são caracterizadas como não corrosivas, pois apresentam $\mathrm{pH}$ inferior a 12,4, não ultrapassando o limite estabelecido pela norma. Em relação à reatividade, as argamassas ensaiadas são caracterizadas como não reativas, pois não apresentam em sua constituição íons cianeto e sulfeto acima dos limites estabelecidos pela norma NBR 10004 (ABNT, 2004) (Tabela 15). Portanto, essas argamassas são classificadas como não perigosas tanto pelo ensaio de corrosividade quanto de reatividade pela NBR 10004 (ABNT, 2004).

A Tabela 16 apresenta o resultado do ensaio de lixiviação das argamassas estudadas.

Tabela 12 - Densidade de massa aparente no estado endurecido e módulo de elasticidade das argamassas

\begin{tabular}{lcccccc}
\hline \multicolumn{1}{c}{ Argamassa } & $\begin{array}{c}\text { Densidade } \\
\text { de massa } \\
\left(\mathbf{k g} / \mathbf{m}^{\mathbf{3}} \mathbf{)}\right.\end{array}$ & $\begin{array}{c}\text { Coeficiente } \\
\text { de variação } \\
\mathbf{( \% )}\end{array}$ & $\mathbf{A V}^{+}$ & $\begin{array}{c}\text { Módulo de } \\
\text { elasticidade } \\
\mathbf{( M P a )}\end{array}$ & $\begin{array}{c}\text { Coeficiente } \\
\text { de variação } \\
\mathbf{( \% )}\end{array}$ & $\mathbf{A V}^{+}$ \\
\hline Referência & $1.919,72$ & 0,55 & $\mathrm{~A}$ & $10.001,39$ & 6,54 & $\mathrm{~A}$ \\
10\% de Areia de fundição & $1.897,57$ & 0,54 & $\mathrm{a} \mathrm{b}$ & $7.763,47$ & 10,84 & $\mathrm{~B}$ \\
30\% de Areia de fundição & $1.881,83$ & 1,05 & $\mathrm{~B}$ & $8.202,37$ & 11,29 & $\mathrm{~B}$ \\
100\% de Areia de fundição & $1.719,74$ & 0,86 & $\mathrm{c}$ & $4.383,18$ & 9,00 & $\mathrm{C}$ \\
\hline
\end{tabular}

Nota: ‘análise de variância: a mesma letra na coluna mostra que não houve diferença significativa pelo teste de Duncan com $5 \%$ de probabilidade de erro.

\section{Figura 4 - Correlação entre (a) módulo de elasticidade e resistência à compressão e (b) densidade de} massa e resistência à compressão das argamassas estudadas

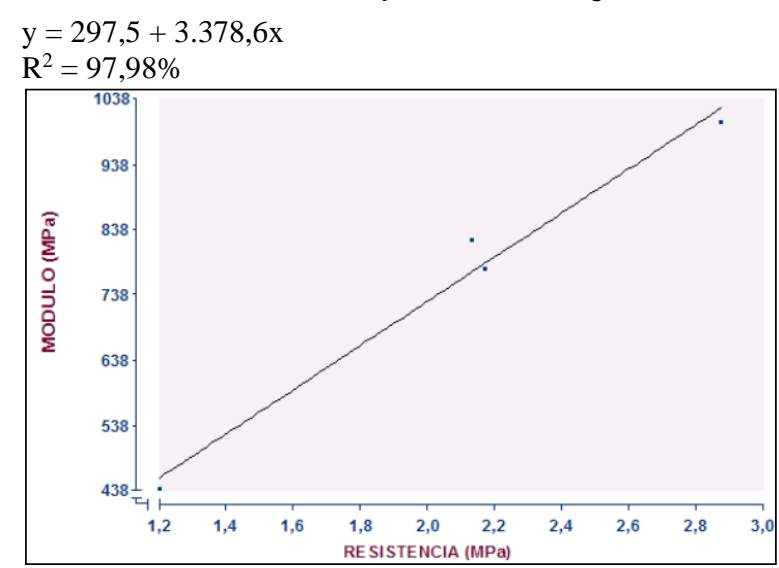

(a)

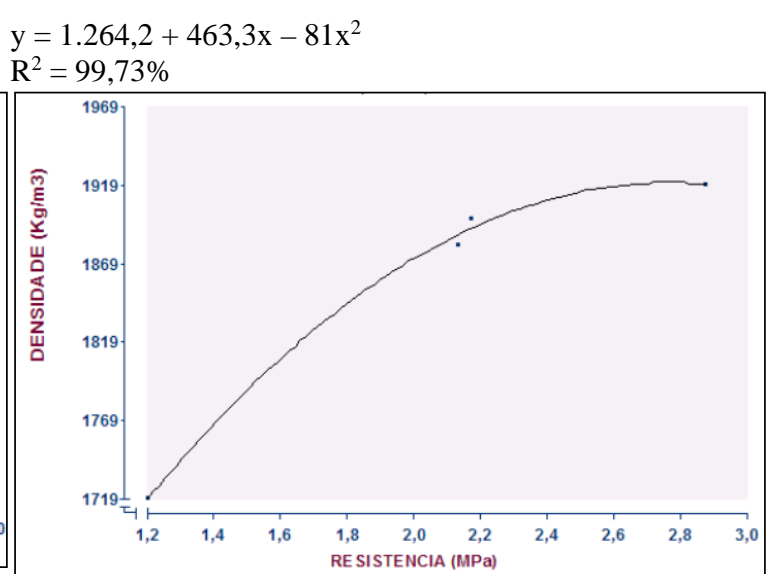

(b)

Tabela 13 - Características físico-químicas das argamassas analisadas

\begin{tabular}{|c|c|c|c|c|}
\hline \multirow{2}{*}{ Característica } & \multicolumn{4}{|c|}{ Classificação } \\
\hline & Referência & $10 \% \mathrm{AF}^{*}$ & $30 \%$ AF* $^{*}$ & $100 \% \mathrm{AF}^{*}$ \\
\hline Aspecto & Sólido (pó) & Sólido (pó) & Sólido (pó) & Sólido (pó) \\
\hline Coloração & Cinza & Cinza & Cinza & Cinza \\
\hline Odor & inodoro & inodoro & inodoro & inodoro \\
\hline Umidade a $105^{\circ} \mathrm{C}(\%)$ & 1,24 & 1,01 & 1,38 & 2,24 \\
\hline $\begin{array}{l}\text { Líquidos livres (método de acordo com } \\
\text { a norma NBR } 12988 \text { (ABNT, 1993) }\end{array}$ & Ausentes & Ausentes & Ausentes & Ausentes \\
\hline
\end{tabular}

Nota: *areia de fundição. 
Tabela 14 - Corrosividade das argamassas estudadas

\begin{tabular}{l|c|c|c|c|c}
\hline \multicolumn{1}{c|}{ Argamassa } & Parâmetro & Unidade & Resultado & Valor recomendado & L.Q. $^{++}$ \\
\hline Referência & & & 12,33 & & \\
$10 \%$ Areia de fundição & pH em água & & 12,02 & 2 a 12,4 & 0,01 \\
30\% Areia de fundição & $(1: 1)$ & - & 12,38 & & \\
$100 \%$ Areia de fundição & & & 12,20 & & \\
\hline
\end{tabular}

Nota: "L.Q. - Limite de quantificação.

Tabela 15 - Reatividade das argamassas estudadas

\begin{tabular}{|c|c|c|c|c|c|}
\hline Argamassa & Parâmetro & Unidade & Resultado & $\begin{array}{l}\text { Limite liberável } \\
\text { por kg de resíduo }\end{array}$ & L.Q. ${ }^{++}$ \\
\hline $\begin{array}{l}\text { Referência } \\
\text { 10\% Areia de fundição } \\
\text { 30\% Areia de fundição } \\
\text { 100\% Areia de fundição }\end{array}$ & $\begin{array}{c}\text { Ácido cianídrico } \\
\text { (HCN) }\end{array}$ & $\mathrm{mg} / \mathrm{kg}$ & $\begin{array}{l}<0,05 \\
<0,05 \\
<0,05 \\
<0,05\end{array}$ & $250 \mathrm{mg}$ de $\mathrm{HCN}$ & 0,05 \\
\hline $\begin{array}{l}\text { Referência } \\
\text { 10\% Areia de fundição } \\
\text { 30\% Areia de fundição } \\
\text { 100\% Areia de fundição }\end{array}$ & $\begin{array}{l}\text { Ácido sulfídrico } \\
\qquad\left(\mathrm{H}_{2} \mathrm{~S}\right)\end{array}$ & $\mathrm{mg} / \mathrm{kg}$ & $\begin{array}{l}<40 \\
<40 \\
<40 \\
<40\end{array}$ & $500 \mathrm{mg}$ de $\mathrm{H}_{2} \mathrm{~S}$ & 40 \\
\hline
\end{tabular}

Nota: +'L.Q. - Limite de quantificação.

Tabela 16 - Resultados do ensaio de lixiviação das argamassas estudadas

\begin{tabular}{l|c|c|c|c|c|c}
\hline \multirow{2}{*}{ Parâmetro } & \multicolumn{5}{|c|}{ Resultados (mg/L) $^{\text {Valores máximos permitidos NBR }}$} & L.Q. $^{++}$ \\
\cline { 2 - 7 } & $\mathbf{R E F}^{+}$ & $\mathbf{1 0 \%} \mathbf{A F}^{*}$ & $\mathbf{3 0 \%} \mathbf{A F}^{*}$ & $\mathbf{1 0 0 \% \mathbf { A F } ^ { * }}$ & $\mathbf{1 0 0 0 4}$ (ABNT, 2004) (mg/L) & 0,01 \\
\hline Arsênio & $<0,01$ & $<0,01$ & $<0,01$ & $<0,01$ & 1,0 & 0,01 \\
Bário & 0,13 & 0,31 & 0,31 & 0,10 & 70,0 & 0,005 \\
Cádmio & $<0,005$ & $<0,005$ & $<0,005$ & $<0,005$ & 0,5 & 0,01 \\
Chumbo & $<0,01$ & $<0,01$ & $<0,01$ & $<0,01$ & 1,0 & 0,01 \\
Cromo total & 0,04 & 0,04 & 0,04 & 0,03 & 5,0 & 0,05 \\
Fenóis totais & $<0,05$ & $<0,05$ & $<0,05$ & $<0,05$ & 1,0 & 0,1 \\
Fluoreto & 0,8 & 1,51 & 0,9 & 1,5 & 150,0 & 0,001 \\
Mercúrio & $<0,001$ & $<0,001$ & $<0,001$ & $<0,001$ & & 0,1 \\
Prata & $<0,01$ & $<0,01$ & $<0,01$ & $<0,01$ & 5,0 & 0,01 \\
Selênio & $<0,01$ & $<0,01$ & $<0,01$ & $<0,01$ & 1,0 & 0,01 \\
\hline
\end{tabular}

Nota: Legenda:

+argamassa de referência;
*areia de fundição; e

+Limite de quantificação.

Como pode ser verificado na Tabela 16, os parâmetros analisados não apresentam concentrações acima dos limites máximos permitidos pela norma NBR 10004 (ABNT, 2004) em nenhuma das argamassas analisadas, caracterizando esses resíduos como não tóxicos, sendo classificados como não perigosos - Classe II.

A Tabela 17 apresenta o resultado do ensaio de solubilização das argamassas estudadas.

Nota-se na Tabela 17 que, dos parâmetros analisados para a argamassa de referência, somente o alumínio apresentou concentrações superiores ao padrão para o ensaio de solubilização (parâmetros indicados em negrito na Tabela 17), provavelmente originária dos aglomerantes (cimento Portland e cal hidráulica) (Tabela 10). Para a argamassa com 10\% de areia de fundição, o alumínio, cromo total e fenóis totais apresentaram concentrações superiores ao padrão. Já para a argamassa com 30\% de areia de fundição, o alumínio e os fenóis totais apresentaram concentrações superiores ao padrão; e para a argamassa com $100 \%$ de areia de fundição, o alumínio, cromo total, fenóis totais e fluoreto apresentaram concentrações superiores ao padrão.

Considerando os resultados obtidos de lixiviação (Tabela 16) e solubilização (Tabela 17) e as características físico-químicas (Tabela 13), todas as argamassas estudadas são classificadas como resíduo não perigoso - Classe II A - não inerte, segundo a NBR 10004 (ABNT, 2004), nos 
parâmetros analisados.

Somente no ensaio de solubilização as argamassas apresentaram valores de concentrações superiores ao padrão, como também havia sido observado para o resíduo de areia de fundição (Tabela 9).

No total, seis parâmetros apresentaram valores de concentrações superiores ao padrão: alumínio, cromo total, fenóis totais, ferro, fluoreto e sódio. Comparando os valores desses parâmetros obtidos para o resíduo de areia de fundição (considerando $100 \%$ do valor obtido para o resíduo de areia de fundição) com os teores obtidos das argamassas com areia de fundição, alguns teores aumentaram e outros reduziram. Na Figura 5 observa-se a redução dos teores de ferro, de fluoreto e de sódio do resíduo de areia de fundição em relação às argamassas com a areia de fundição. Neste caso, os aglomerantes (cimento Portland e cal hidráulica) podem ter encapsulado ou envolvido os componentes, não permitindo sua solubilização. Brito e Soares (2009) comentam que a estabilização por solidificação, uma vez que os contaminantes estão retidos ou aprisionados no interior da partícula de cimento, ocorre por reações químicas entre os contaminantes e aglomerantes e/ou ocorre por processos de retenção física dos contaminantes. Esses autores concluíram que o uso de cimento, de hidróxido de cálcio e de bentonita sólida se mostrou ideal para a retenção de metais pesados, evitando sua lixiviação e solubilização para o meio ambiente. Também foi observada por Hamilton e Sammes (1999) a retenção de metais pesados estabilizados com matrizes de cimento Portland. Pablos (2008) verificou a estabilização do resíduo sólido gerado pelo descarte das areias de fundição aglomeradas com argila, através do ensaio de solubilização, em matrizes solidificadas de cimento Portland, melhoradas através de adições de argila bentonita e/ou sílica ativa. Todos os trabalhos apresentam resultados semelhantes aos obtidos neste estudo.

Tabela 17 - Resultado do ensaio de solubilização das argamassas estudadas

\begin{tabular}{|c|c|c|c|c|c|c|}
\hline \multirow[b]{2}{*}{ Parâmetro } & \multicolumn{4}{|c|}{ Resultados (mg/L) } & \multirow{2}{*}{$\begin{array}{c}\text { Valor máximo } \\
\text { permitido NBR } 10004 \\
(\mathrm{ABNT}, 2004)(\mathrm{mg} / \mathrm{L})\end{array}$} & \multirow[b]{2}{*}{ L.Q..$^{++}$} \\
\hline & $\mathbf{R E F}^{+}$ & $10 \% \mathbf{A F}^{*}$ & $30 \% \mathbf{A F}^{*}$ & $100 \% \mathrm{AF}^{*}$ & & \\
\hline Alumínio & 1,2 & 1,1 & 1,3 & 2,07 & 0,2 & 0,1 \\
\hline Arsênio & $<0,01$ & $<0,01$ & $<0,01$ & $<0,01$ & 0,01 & 0,01 \\
\hline Bário & 0,06 & 0,07 & 0,12 & 0,03 & 0,7 & 0,1 \\
\hline Cádmio & $<0,005$ & $<0,005$ & $<0,005$ & $<0,005$ & 0,005 & 0,005 \\
\hline Chumbo & $<0,01$ & $<0,01$ & $<0,01$ & $<0,01$ & 0,01 & 0,01 \\
\hline Cloreto & $<0,5$ & $<5$ & $<5$ & $<5$ & 250,0 & 5 \\
\hline Cobre & $<0,005$ & $<0,005$ & $<0,005$ & $<0,005$ & 2,0 & 0,005 \\
\hline Cromo total & 0,04 & 0,06 & 0,02 & 0,06 & 0,05 & $\mathbf{0 , 0 1}$ \\
\hline Fenóis totais & 0,01 & 0,03 & $\mathbf{0 , 1 0}$ & 0,23 & 0,01 & 0,01 \\
\hline Ferro & $<0,05$ & $<0,05$ & $<0,05$ & $<0,05$ & 0,3 & 0,05 \\
\hline Fluoreto & $<1,0$ & 0,9 & $<1,0$ & 1,7 & 1,5 & $\mathbf{0 , 1}$ \\
\hline Manganês & $<0,01$ & $<0,01$ & $<0,01$ & $<0,01$ & 0,1 & 0,01 \\
\hline Mercúrio & $<0,001$ & $<0,001$ & $<0,001$ & $<0,001$ & 0,001 & 0,001 \\
\hline $\begin{array}{l}\text { Nitrato (expresso } \\
\text { em N) }\end{array}$ & $<0,1$ & $<0,1$ & $<0,1$ & $<0,1$ & 10,0 & 0,1 \\
\hline Prata & $<0,01$ & $<0,01$ & $<0,01$ & $<0,01$ & 0,05 & 0,01 \\
\hline Selênio & $<0,01$ & $<0,01$ & $<0,01$ & $<0,01$ & 0,01 & 0,01 \\
\hline Sódio & 20,27 & 19,58 & 50,67 & 130,57 & 200,0 & 0,01 \\
\hline $\begin{array}{l}\text { Sulfatos (expresso - } \\
\mathrm{SO}_{4} \text { ) }\end{array}$ & 36 & 39 & 21 & 47 & 250,0 & 5 \\
\hline Surfactantes & 0,2 & $<0,1$ & $<0,1$ & 0,1 & 0,5 & 0,5 \\
\hline Zinco & $<0,01$ & $<0,01$ & $<0,01$ & $<0,01$ & 5,0 & 0,01 \\
\hline
\end{tabular}

\section{Nota: Legenda:}

targamassa de referência;

*areia de fundição; e

Himite de quantificação. 
Já na Figura 6 observa-se o aumento dos teores de alumínio, de fenóis totais e de cromo total do resíduo de areia de fundição em relação às argamassas com areia de fundição. Em relação aos teores de alumínio, esse resultado já era esperado, pois os aglomerantes utilizados (cimento Portland e cal hidráulica) possuem em suas composições teores de alumínio (9,03\% no cimento Portland e 8,09\% na cal hidráulica - Tabela 10) superiores aos do resíduo de areia de fundição (teor de 2,08\% Tabela 4). Assim, as composições de argamassas confeccionadas com esses materiais também apresentaram maiores teores. Esses resultados foram semelhantes ao obtido por Armange et al. (2005). Já para os teores de fenóis totais e de cromo total das argamassas, podem ter ocorrido reações químicas, aumentado, assim, o teor desses componentes em relação à areia de fundição.

Figura 5 - Porcentagem dos teores de ferro, de fluoretos e de sódio das argamassas com areia de fundição em relação ao resíduo de areia de fundição

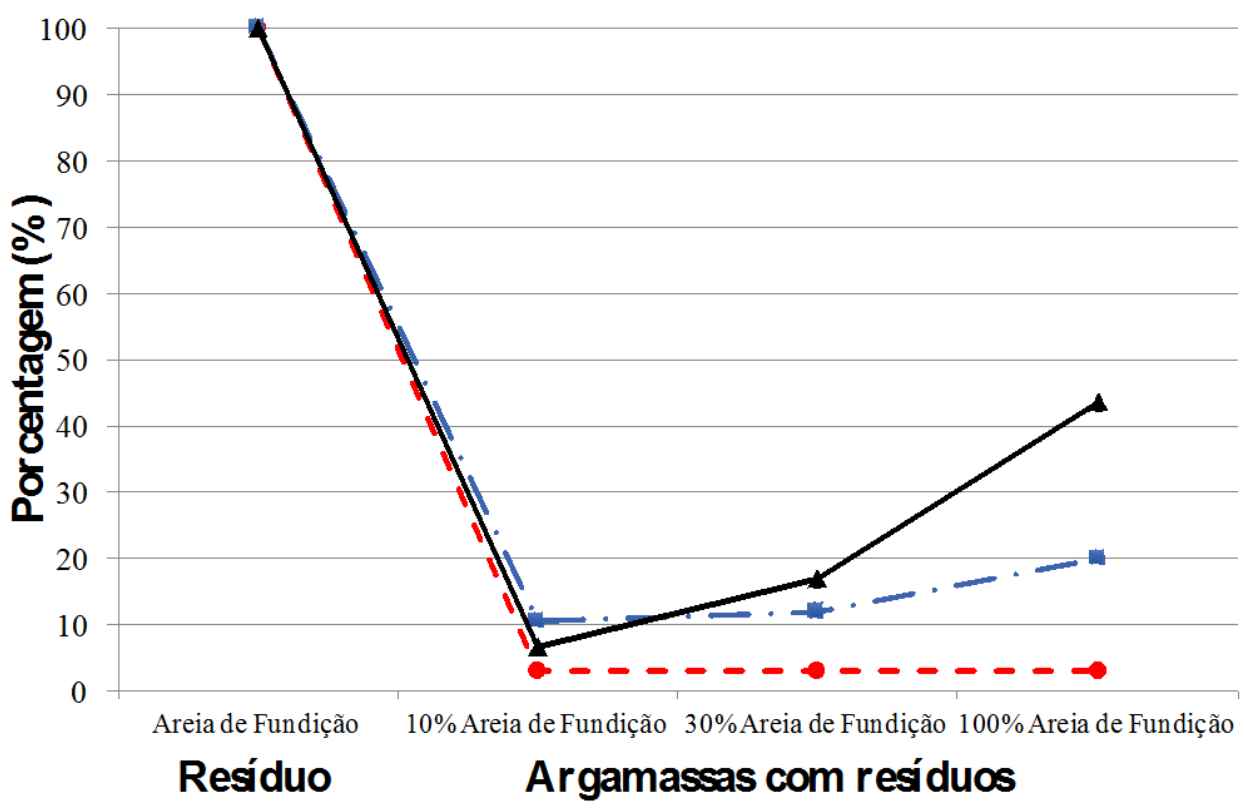

$\rightarrow$-Ferro $\quad \rightarrow$ Fluoreto $\quad$ \Sódio 
Figura 6 - Porcentagem dos teores de alumínio, de fenóis totais e de cromo total das argamassas com areia de fundição em relação ao resíduo de areia de fundição

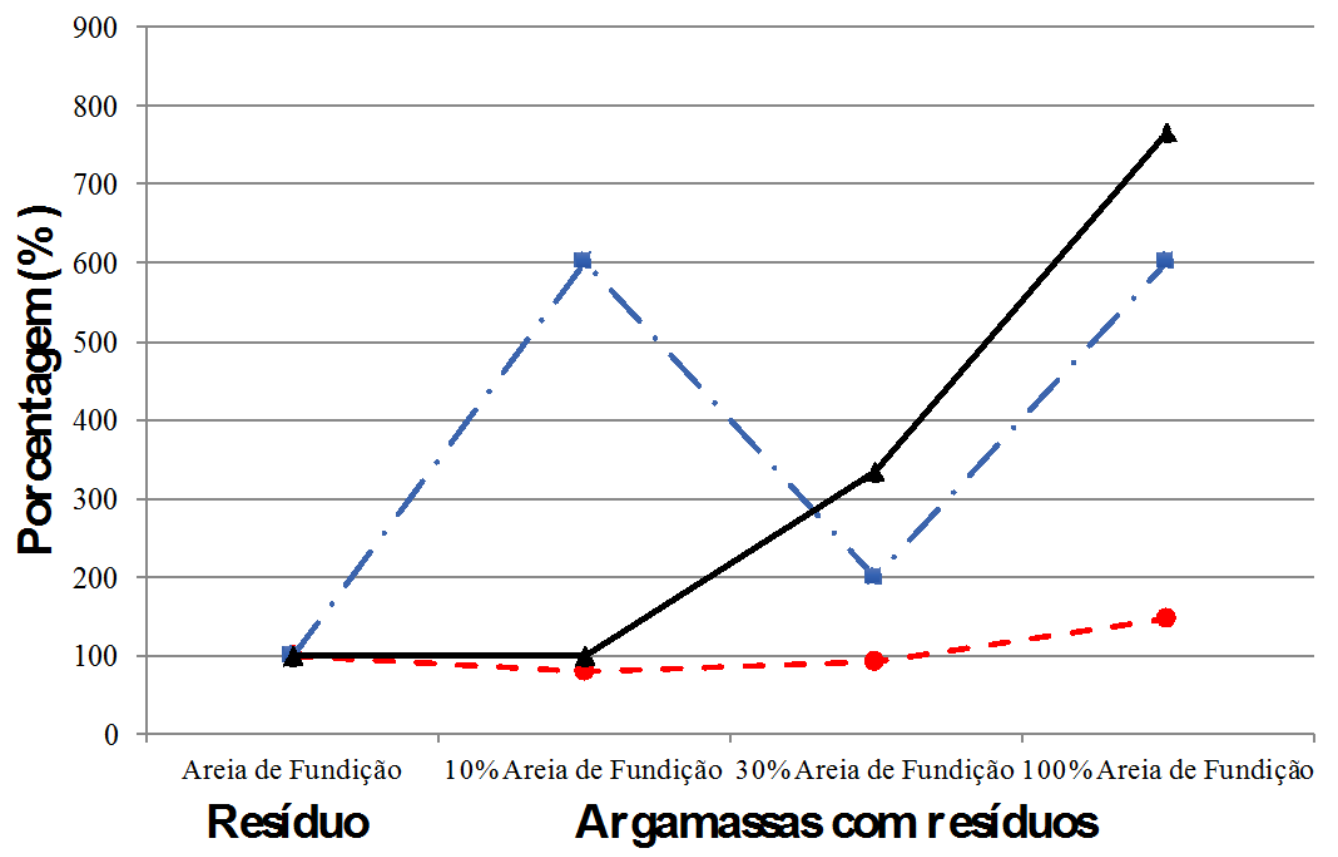

$\rightarrow$-Alumínio $\rightarrow$ Cromo Total $\pitchfork$ Fenóis Totais

\section{Conclusões}

Com os resultados obtidos de caracterização dos agregados miúdos, areia natural e resíduo de areia de fundição, verificou-se diferença na granulometria, em que o resíduo de areia de fundição apresentou-se mais fino. Além disso, o resíduo de areia de fundição apresentou teores de sílica $\left(\mathrm{SiO}_{2}\right)$ e de perda ao fogo superiores ao obtido para a areia natural. No ensaio de solubilização do resíduo, verificou-se que a concentração de alumínio, de fenóis totais, de ferro, de fluoreto e de sódio foram superiores aos limites recomendados por norma.

No estado fresco, a argamassa com 100\% de substituição da areia natural pela areia de fundição demandou maior quantidade de água para manter o índice de consistência (flow table), diferentemente das argamassas com $10 \%$ e $30 \%$ de areia de fundição (semelhante à relação água-materiais secos da argamassa referência). A retenção de água da argamassa de referência foi superior ao obtido para as argamassas com resíduo de areia de fundição.

Já no estado endurecido, a substituição da areia natural pelo resíduo de areia de fundição influenciou negativamente nas resistências. Os valores de resistência à compressão para a argamassa com $10 \%$ e $30 \%$ não tiveram diferença significativa entre si, mas os valores foram menores do que para a argamassa de referência. Para a argamassa com $100 \%$ de areia de fundição os valores obtidos foram $57 \%$ menores em relação à argamassa de referência. Para a argamassa com $100 \%$ de areia de fundição houve redução nos valores obtidos tanto da densidade quanto do módulo de elasticidade. Também foi obtida uma boa correlação entre os valores obtidos de resistência à compressão e módulo de elasticidade, além dos valores obtidos de resistência à compressão e densidade de massa no estado endurecido.

Em relação aos resíduos da areia de fundição e às argamassas estudadas, foram classificados como não perigosos tanto pelo ensaio de corrosividade quanto de reatividade e não apresentaram nenhuma concentração de extratos lixiviados superior ao limite da norma. No caso da argamassa de referência, o ensaio de solubilização mostrou que a concentração em alumínio foi maior do que a permitida pela norma NBR 10004 (ABNT, 2004). Comparando o ensaio de solubilização do resíduo de areia de fundição com das argamassas com a areia de fundição, houve diminuição nos teores de ferro, de fluoreto e de sódio, e aumento nos teores de alumínio, de cromo total e de fenóis totais. O resíduo de areia de fundição e as argamassas com resíduos foram classificados como não perigosos Classe II A - não inerte, segundo a NBR 10004 (ABNT, 2004). 


\section{Referências}

AGGARWAL, Y.; SIDDIQUE, R. Microstructure and Properties of Concrete Using Bottom Ash and Waste Foundry Sand as Partial Replacement of Fine Aggregates. Construction and Building Materials, v. 54, p. 210-223, 2014.

ARMANGE, L. C. et al. Utilização de Areia de Fundição Residual Para Uso em Argamassa. Revista Matéria, v. 10, n. 1, p. 51-62, 2005.

ARMANGE, L. C. Utilização de Areia de Fundição Residual Para Uso em Argamassa. Florianópolis, 2005. 104 f. Dissertação (Mestrado em Engenharia de Materiais) - Escola de Engenharia, Universidade Federal de Santa Catarina, Florianópolis, 2005.

ASSOCIAÇÃO BRASILEIRA DE FUNDIÇÃO. Índices Setoriais - ABIFA. Disponível em: $<$ http://www.abifa.org.br/indices-setoriais>. Acesso em: 25 abr. 2016.

ASSOCIAÇÃO BRASILEIRA DE NORMAS TÉCNICAS. NBR 10004: resíduos sólidos: classificação. Rio de Janeiro, 2004.

ASSOCIAÇÃO BRASILEIRA DE NORMAS TÉCNICAS. NBR 12988: líquidos livres: verificação em amostra de resíduos: método de ensaio. Rio de Janeiro, 1993.

\section{ASSOCIAÇÃO BRASILEIRA DE NORMAS} TÉCNICAS. NBR 13276: argamassa para assentamento e revestimento de paredes e tetos: preparo da mistura e determinação do índice de consistência. Rio de Janeiro, 2005a.

ASSOCIAÇÃO BRASILEIRA DE NORMAS TÉCNICAS. NBR 13277: argamassa para assentamento e revestimento de paredes e tetos: determinação da retenção de água. Rio de Janeiro, $2005 b$.

\section{ASSOCIAÇÃO BRASILEIRA DE NORMAS}

TÉCNICAS. NBR 13279: argamassa para assentamento e revestimento de paredes e tetos: determinação da resistência à tração na flexão e à compressão. Rio de Janeiro, 2005d.

\section{ASSOCIAÇÃO BRASILEIRA DE NORMAS}

TÉCNICAS. NBR 13280: argamassa para assentamento e revestimento de paredes e tetos: determinação da densidade de massa aparente no estado endurecido. Rio de Janeiro, 2005e.

\section{ASSOCIAÇÃO BRASILEIRA DE NORMAS} TÉCNICAS. NBR 15630: argamassa para assentamento e revestimento de paredes e tetos: determinação do módulo de elasticidade dinâmico através da propagação de onda ultra-sônica. Rio de Janeiro, 2009b.
ASSOCIAÇÃO BRASILEIRA DE NORMAS TÉCNICAS. NBR 7215: cimento Portland: determinação da resistência à compressão. Rio de Janeiro, 1996.

ASSOCIAÇÃO BRASILEIRA DE NORMAS TÉCNICAS. NBR NM 23: cimento Portland e outros materiais em pó: determinação da massa específica. Rio de Janeiro, 2001.

ASSOCIAÇÃO BRASILEIRA DE NORMAS TÉCNICAS. NBR NM 248: agregados: determinação da composição granulométrica. Rio de Janeiro, 2003a.

ASSOCIAÇÃO BRASILEIRA DE NORMAS TÉCNICAS. NBR NM 45: agregados: determinação da massa unitária e do volume de vazios. Rio de Janeiro, 2006.

\section{ASSOCIAÇÃO BRASILEIRA DE NORMAS} TÉCNICAS. NBR NM 46: agregados: determinação do material fino que passa através da peneira $75 \mu \mathrm{m}$ por lavagem. Rio de Janeiro, 2003b.

\section{ASSOCIAÇÃO BRASILEIRA DE NORMAS} TÉCNICAS. NBR NM 52: agregados: determinação da massa específica e massa específica aparente. Rio de Janeiro, 2009a.

\section{ASSOCIAÇÃO BRASILEIRA DE NORMAS}

TÉCNICAS.. NBR 13278: argamassa para assentamento e revestimento de paredes e tetos: determinação da densidade de massa e do teor de ar incorporado. Rio de Janeiro, 2005c.

BRITO, A. L. F.; SOARES, S. R. Avaliação da Integridade e da Retenção de Metais Pesados em Materiais Estabilizados por Solidificação.

Engenharia Sanitária Ambiental, v. 14, n. 1, p. 39-48, jan./mar. 2009.

CINCOTTO, M. A.; QUARCIONI V. A.; JOHN, V. M. J. F. A Cal na Construção Civil. In: ISAIA, G.C. (Ed.). Materiais de Construção Civil e Princípios de Ciências e Engenharia de Materiais. São Paulo: Ipsis, 2007.

DAL MAGRO, A. C.; MORAES, C. A. M.; KULAKOWSKI, M. P. Influência da Areia Fenólico-Alcalina Usada de Fundição na Resistência à Compressão e na Absorção de Água em Concreto. In: SALÃO DE INICIAÇÃO CIENTÍFICA, 11., Porto Alegre, 2010. Anais... Porto Alegre, 2010.

DAMASCENO, B. C.; AMÉRICO, J. D. Utilização de Areia de Fundição na Produção de Blocos de Concreto sem Função Estrutural. In: CONGRESSO INTERNO DE INICIAÇÃO CIENTÍFICA, 20., Campinas, 2012. Anais... Campinas, 2012. 
DOLCH, W. L. Air Entraining Admixtures. In: RAMACHANDRAN, V. S. (Ed.). Concrete Admixtures Handbook: properties, science and technology. New Jersey: Noyes, 1984.

FERREIRA, K. B.; FERREIRA, J. A.; SILVA, L. O. N. Emprego de Areia de Fundição Ligada Quimicamente em Argamassas Para Construção Civil. In: CONGRESSO BRASILEIRO DE ENGENHARIA SANITÁRIA E AMBIENTAL, 26., Porto Alegre, 2011. Anais... Porto Alegre, 2011.

GENZLER, F. W. Avaliação da Reutilização da Areia de Fundição Descartada na Empresa FUNDIMISA Para a Produção de Pisos de Concreto. In: JORNADA ACADÊMICA INTEGRADA, 25., Santa Maria: UFSM, Santa Maria, 2010. Anais... Santa Maria: UFSM, 2010.

GUIMARÃES, J. E. P. A Cal: fundamentos e aplicações na engenharia civil. 2. ed. São Paulo: Pini, 2002.

HAMILTON, I. W.; SAMMES, N. M. Encapsulation of Steel Foundry Bag House Dusts in Cement Mortar. Cement and Concrete Research, v. 29, p. 55-61, 1999.

KHANDURI, A. Properties of Mortar Incorporating Waste Foundry Sand. Patiala, 2010. 62 f. Thesis (Master of Engineering in Civil Engineering - Structures) - Thapar University, Patiala, India, 2010.

KHATIB, J. M.; HERKI, B. A.; KENAI, S. Capillarity of Concrete Incorporating Waste Foundry Sand. Construction and Building Materials, v. 47, p. 867-871, 2013.

KRUGER, P.; CABRAL, L. A.; SOUZA, V. F. C. Confecção de Argamassa Utilizando Areia Residual do Processo de Fundição. In: ENCONTRO DE ENGENHARIA E TECNOLOGIA DOS CAMPOS GERAIS, 8., Ponta Grossa, 2013. Anais... Ponta Grossa, 2013.

LIMA, J.; BETIOLI, A. M. Levantamento dos Materiais e Tecnologias Empregadas Pelas Empresas de Construção Civil na Região de Criciúma. Revista Técnico Científica (IFSC), v. 3, n. 1, p. 321-329, 2012.

\section{LOPES, L. R. N. Avaliação da Redução dos}

Resíduos Sólidos de Areia Resinada em Fundição de Aço Através da Recuperação Térmica. Salvador, 2009. 94 f. Dissertação (Mestrado Profissional Gerenciamento e Tecnologias Ambientais no Processo Produtivo) Escola Politécnica, Universidade Federal da Bahia, Salvador, 2009.
MELLO, O. J. Estudo da Viabilidade da Reutilização de Resíduo de Areia Verde de Fundição em Argamassas Colantes: enfoque ambiental. 2004. 159 f. Dissertação (Mestrado em Engenharia Ambiental) - Centro de Ciências Tecnológicas, Universidade Regional de Blumenau, Blumenau, 2004.

MIGUEL, T. F. et al. Estudo da Viabilidade de Aplicação de Areia de Fundição da Região de Criciúma em Argamassas. In: CONGRESSO BRASILEIRO DO CONCRETO, 57., Bonito, 2015. Anais... Bonito: Ibracon, 2015.

PABLOS, J. M. Estudo Para a Reutilização do Resíduo Sólido Constituído Pelas Areias de Fundição Aglomeradas Com argila, Através da Técnica de Solidificação/Estabilização em Matrizes de Cimento Portland, Para Aplicação no Setor da Construção Civil. São Carlos, 2008. 133 p. Tese (Doutorado em Arquitetura e Urbanismo) - Escola de Engenharia, Universidade de São Paulo, São Carlos, 2008.

ROCHA, J. P. A.; LUZ, C. A.; HERMANN, A. Influência da Areia de Fundição nas Propriedades do Estado Fresco do Concreto Auto-Adensável. In: SEMINÁRIO DE INICIAÇÃO CIENTÍFICA E TECNOLÓGICA, 17., Pato Branco, 2012. Anais... Pato Branco, 2012.

SARASWATI, P. C. et al. Application of Waste Foundry Sand for Evolution of Low-Cost Concrete. International Journal of Engineering Trends and Technology, v. 4, n. 10, p. 42814286, Oct. 2013.

SCHEUNEMANN, R. Regeneração de Areia de Fundição Através de Tratamento Químico Via Processo Fenton. Florianópolis, 2005. $71 \mathrm{f}$. Dissertação (Mestrado em Engenharia Química) Escola de Engenharia, Universidade Federal de Santa Catarina, Florianópolis, 2005.

SIDDIQUE, R.; SCHUTTER, G.; NOUMOWEC, A. Effect of Used-Foundry Sand on the Mechanical Properties of Concrete. Construction and Building Materials, v. 23, p. 976-980, 2008.

SINGH, G.; SIDDIQUE, R. Effect of Waste Foundry Sand (WFS) as Partial Replacement of Sand on the Strength, Ultrasonic Pulse Velocity and Permeability of Concrete. Construction and Building Materials, v. 26, p. 416-422, 2012.

SWAPNA, S. S.; PATIL, S. G. Utilization of Foundry Waste sand as a Masonry Mortar. IOSR Journal of Mechanical and Civil Engineering, v. 12, n. 6, p. 49-54, Nov./Dec. 2015. 
TOLEDO, A. L. S. et al. Avaliação da Possibilidade de Substituição de Areia Natural Por de Areia de Fundição em Argamassas de Cimento Portland. In: SEMINÁRIO DE PESQUISA, EXTENSÃO E INOVAÇÃO DO IFSC, Lages, 2013. Anais... Lages: IFSC, 2013.

WATANABE, F. A. Estudo Sobre a Utilização de Fundição Residual Como Agregado na Confeç̧ão de Pavimentos de Concreto.

Florianópolis, 2004. 121 f. Dissertação (Mestre em Ciência e Engenharia de Materiais) - Escola de Engenharia, Universidade do Estado de Santa Catarina, Florianópolis, 2004.

\section{Agradecimentos}

Agradecimento especial ao Instituto Federal de Santa Catarina (IFSC) pelo financiamento por meio de bolsas de iniciação científica concedidas e verba no Edital n 19/2014/PROPPI.

J uliana Machado Casali

Departamento Acadêmico de Construção Civil | Instituto Federal de Santa Catarina | Avenida Mauro Ramos, 950 | Florianópolis - SC Brasil | CEP 88020-300 | Tel.: (48) 3211-6143 | E-mail: juliana.casali@ifsc.edu.br

Thainá Fortunato Miguel

Departamento de Construção Civil | Instituto Federal de Santa Catarina | Rodovia SC 443 - 845, Vila Rica | Criciúma - SC - Brasil |

CEP 88813-600 | Tel.: (48) 3462-5015 | E-mail: thaina.fortunatto@gmail.com

\section{Caroline Castanhetti Felizardo}

Departamento de Construção Civil | Instituto Federal de Santa Catarina | E-mail: ca.stanhette@hotmail.com

\section{Natacha dos Santos Meira}

Departamento de Construção Civil | Instituto Federal de Santa Catarina | E-mail: natachasantos11@hotmail.com

Lucas Dominguini

Departamento de Ciências Naturais e Matemática | Instituto Federal de Santa Catarina | Tel.: (48) 3462-5044 |

E-mail: lucas.dominguini@ifsc.edu.br

\section{Andrea Murillo Betioli}

Departamento Acadêmico de Construção Civil | Instituto Federal de Santa Catarina | Tel.: (48) 3211-6143 |

E-mail: andrea.betioli@ifsc.edu.br

\section{Revista Ambiente Construído}

Associação Nacional de Tecnologia do Ambiente Construído

Av. Osvaldo Aranha, 99 - 3o andar, Centro

Porto Alegre - RS - Brasil

CEP 90035-190

Telefone: +55 (51) 3308-4084

Fax: +55 (51) 3308-4054

www. seer. ufrgs. br/ ambienteconstruido

E-mail: ambienteconstruido@ufrgs.br 